\title{
Impact of the Extended Boreal Summer Intraseasonal Oscillation on Western North Pacific Tropical Cloud Cluster Genesis Productivity
}

\author{
HAIKUN ZHAO \\ Key Laboratory of Meteorological Disaster, Ministry of Education, and Joint International Research Laboratory of Climate and \\ Environment Change, and Collaborative Innovation Center on Forecast and Evaluation of Meteorological Disaster, \\ and Pacific Typhoon Research Center, Nanjing University of Information Science and Technology, Nanjing, China \\ SHAOHUA CHEN \\ Key Laboratory of Meteorological Disaster, Ministry of Education, Nanjing University of Information Science and \\ Technology, Nanjing, China \\ PHILIP J. KLOTZBACH \\ Department of Atmospheric Science, Colorado State University, Fort Collins, Colorado \\ G. B. RAGA \\ Centro de Ciencias de la Atmósfera, Universidad Nacional Autónoma de México, Mexico City, Mexico
}

(Manuscript received 28 February 2018, in final form 30 August 2018)

\begin{abstract}
Tropical cloud clusters (TCCs) are traditionally viewed as precursors of tropical cyclone (TC) genesis. Most studies have focused on the impact of the extended boreal summer intraseasonal oscillation (ISO) on TC activity over the western North Pacific (WNP), while the modulation of the ISO on WNP TCC genesis productivity (TCCGP), that is, the ratio of TC to TCC counts, has been investigated much less frequently. This study suggests that the extended boreal summer ISO modulates WNP TCCGP, with higher (lower) TCCGP during convectively active (inactive) ISO phases. Changes in TCCGP are found to be closely associated with changes of large-scale environmental factors. During the convectively active ISO phase, significantly increased TCCGP is associated with strengthened low-level cyclonic circulation anomalies and increased midlevel relative humidity anomalies over the WNP basin. The genesis potential index (GPI) contains several large-scale environmental variables demonstrated to relate to TCs and TCCs. The GPI can adequately depict the ISO modulation of WNP TCCGP through its alterations of large-scale parameters. Low-level vorticity makes the largest contribution to the change of TCCGP with a secondary contribution from midlevel relative humidity. Interestingly, the nonlinear GPI terms make comparable contributions, which can be partly explained by the synoptic-scale wave activity associated with the ISO mode. Stronger (weaker) 3-8-day synoptic-scale wave train intensity and increased (decreased) low-level eddy kinetic energy are found to be associated with the enhanced (weakened) monsoon circulation over the WNP basin during convectively active (inactive) ISO phases.
\end{abstract}

\section{Introduction}

The western North Pacific (WNP) experiences an average of 26 named tropical cyclones (TCs) per year, making it the most active of any of the globe's TC basins on an average basis (Chan 2005). The significant threat of WNP TCs to property and life in China and throughout

Corresponding author: Dr. Haikun Zhao, zhk2004y@gmail.com east Asia (Zhang et al. 2009) demonstrates the critical need for improved extended-range prediction of TC activity. Currently, short-range forecasts and seasonal outlooks for WNP TC activity are routinely issued (Waliser et al. 2006; Camargo et al. 2007). However, intraseasonal prediction of TC activity remains challenging because of the limited understanding of associated physical mechanisms on these intermediate time scales (Slingo et al. 1996; Waliser et al. 2003; Lin et al. 2006; Jiang et al. 2012a,b). 
Vigorous intraseasonal oscillations (ISOs) in the extended boreal summer (May-October) are observed over the WNP (Huang et al. 2011; Li and Zhou 2013a,b; Li and Wang 2005; Zhao et al. 2015a,b; Li et al. 2017). The Madden-Julian oscillation (MJO; Madden and Julian 1971, 1972) is an eastward-moving equatorially propagating ISO mode with a prevailing period of $\sim 30-60$ days. The real-time multivariate MJO (RMM) index, developed by Wheeler and Hendon (2004), uses multivariate empirical orthogonal function (EOF) modes averaged in the near-equatorial region from $15^{\circ} \mathrm{S}$ to $15^{\circ} \mathrm{N}$ of both outgoing longwave radiation (OLR; a good proxy for convection) and zonal winds at 850 and $200 \mathrm{hPa}$. This index is the most widely used for representing MJO activity (e.g., Leroy and Wheeler 2008; Wheeler et al. 2009; Gottschalck et al. 2010; Rashid et al. 2011). The equatorially symmetric nature of the RMM index makes it an excellent measure of the equatorial eastward-propagating mode- the MJO. However, since the RMM index is designed to depict year-round MJO activity, it is not expected to fully represent the seasonality of the ISO, especially during the peak of the boreal summer when ISO activity is farthest from the equator. Over the extended boreal summer, the prominent north-northeastward movement of the ISO mode with an approximate 30-60-day period over the WNP in the East Asian monsoon region and eastward propagation along the equator has been widely documented (Yasunari 1979; Wang and Rui 1990; Hsu et al. 2004; Jiang et al. 2004; Zhao et al. 2015a,b). This propagation significantly modulates WNP TC activity by altering environmental conditions and wave accumulation through barotropic energy conversion (Camargo et al. 2009; Huang et al. 2011; Li and Zhou 2013a,b; Zhao et al. 2015a,b, 2016). Using the genesis potential index (GPI) proposed by Emanuel and Nolan (2004), studies have suggested that midlevel relative humidity and low-level vorticity are the two largest contributors to WNP and global TC genesis on intraseasonal time scales (Camargo et al. 2009; Huang et al. 2011; Jiang et al. 2012a; Zhao et al. 2015a,b). There is a consensus that more TCs are observed over the WNP basin during the convectively active phase of the ISO (Camargo et al. 2009).

Tropical cloud clusters (TCCs) are typically viewed as the precursors of TCs (Hennon et al. 2013; Kerns and Chen 2013). Given certain favorable large-scale conditions such as enhanced low-level convergence, vorticity, and atmospheric moisture, a TCC is more likely to develop into a TC (Gray 1998). While there have been numerous studies investigating the relationship between the ISO and TC activity, the effect of the ISO on TCCs and especially on TCC genesis productivity (TCCGP) has been less studied. Hennon et al. (2013) proposed
TCCGP as an efficiency metric that measures the ratio of TCs to TCC counts. They produced an extensive global climatology of TCCGP for the period of 1982 2009 by using the global TCC data developed by Hennon et al. (2011) and found that the WNP has the highest TCCGP in the world. Teng et al. (2014) analyzed the influence of El Niño-Southern Oscillation (ENSO) on WNP TCCs and TCCGP in terms of changes in environmental parameters. They found that the number of TCCs correlated well with ENSO in both the western part of the WNP and in the eastern part of the WNP. The TCCGP was not affected by the ENSO signal in either of these two subregions, however, indicating that the influence of ENSO on TC numbers in each subregion of the WNP was mainly due to changes in TCC number, not variations in the TCCGP. Given the changes in large-scale conditions associated with the dominant ISO mode over the extended boreal summer, we can ask the question, does the boreal summer ISO modulate TCCGP over the WNP basin?

This study provides an exploratory analysis of the impact of the extended boreal summer ISO on WNP TCCGP. The rest of this study is organized as follows. Section 2 describes the datasets used, the definition of TCCGP, the methodology to identify the extended boreal summer ISO mode, and the diagnostic tool used to examine the relative importance of large-scale parameters affecting the TCCGP. Section 3 investigates the modulation of WNP TCCs, TCs, and TCCGP by the ISO. Section 4 discusses the changes in large-scale environmental factors associated with the ISO and further explores the relative roles of large-scale environmental factors affecting TCCGP over the WNP basin. A summary is given in section 5 .

\section{Data and methods}

\section{a. Data and definition of TCCGP}

OLR is a good proxy for convection and has often been used to infer aspects of the ISO (Wheeler and Hendon 2004; Lee et al. 2013; Li and Zhou 2013a,b; Liu et al. 2016). Daily mean OLR derived from the National Oceanic and Atmospheric Administration (NOAA) polar-orbiting satellites on a $2.5^{\circ}$ latitude-longitude grid from 1982 to 2009 (Liebmann and Smith 1996) is used to identify the extended boreal summer ISO mode over the WNP basin. Daily winds, relative humidity, air temperature, and sea surface temperature (SST) derived from the European Centre for Medium-Range Weather Forecasts (ECMWF) interim reanalysis (ERA-Interim; Dee et al. 2011), with a horizontal resolution of $1.5^{\circ} \times$ $1.5^{\circ}$, are used to investigate the impacts of large-scale factors associated with the ISO mode. 

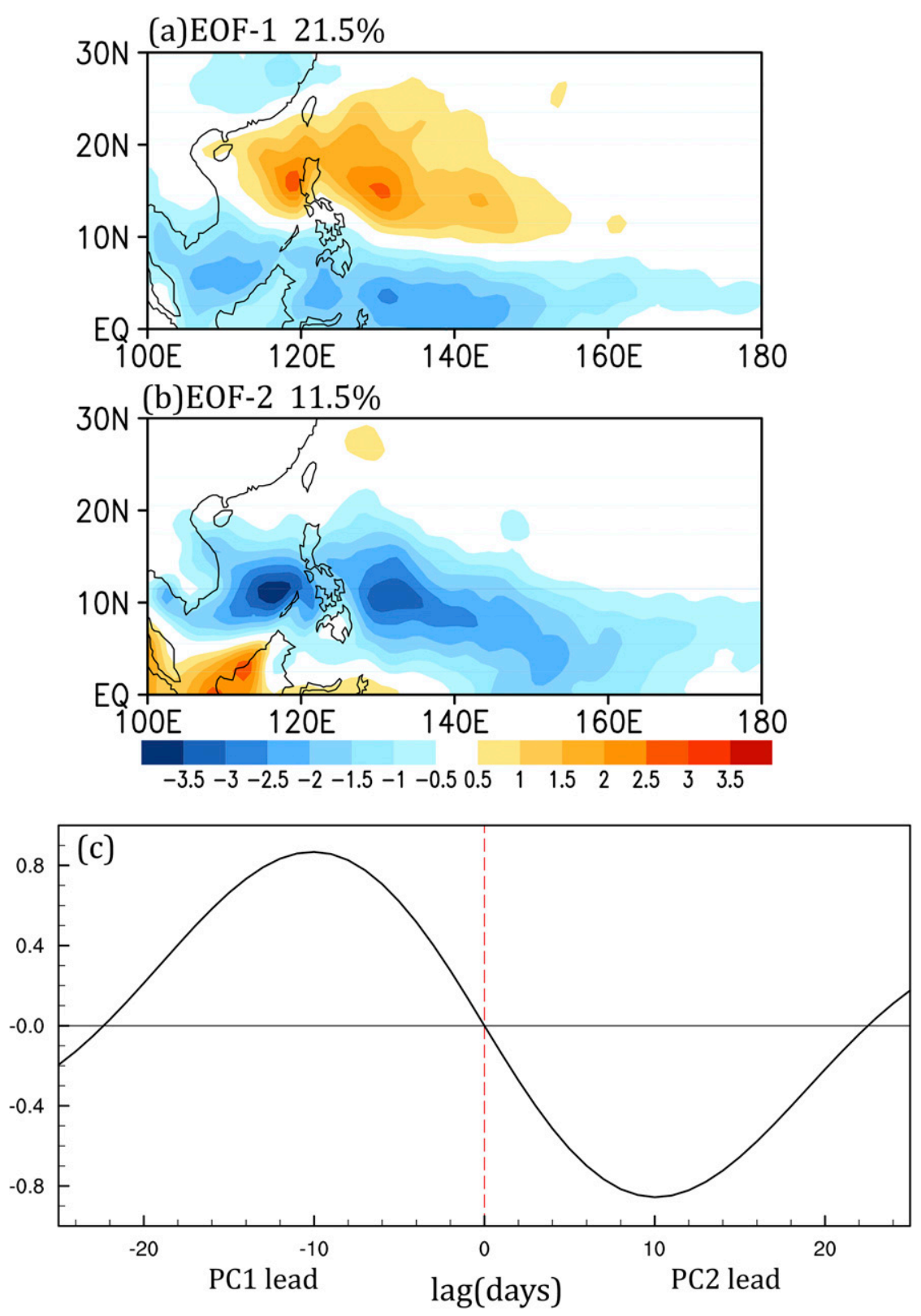

FIG. 1. (a) EOF-1 and (b) EOF-2 of the 30-60-day filtered OLR anomalies and (c) lead-lag correlation coefficients between PC1 and PC2 from May to October for the period of 19822009.

We use global TCC data, version v01r01, described in Hennon et al. (2011; available from http://www.atms. unca.edu/chennon/research/tcc.shtml). TCCs were objectively identified in Gridded Satellite (GridSat) calibrated IR data (Knapp et al. 2011) based on atmospheric convection characteristics primarily based on size, shape, and persistence. Hennon et al. (2011) provide more details on the objective identification of TCCs and the International Best Track Archive for Climate Stewardship (IBTrACS) data that were obtained from all World Meteorological Organization (WMO) Regional Specialized Meteorological Centers (RSMCs) best track data (Knapp et al. 2010). This dataset was used to determine whether a TCC developed into a TC. By comparing the formation of developing TCCs with the IBTrACS global best track dataset, Knapp et al. (2010) identify which clusters developed into a TC. TCCs are tracked through time by an automated tracker that searches back in the 3-hourly GridSat data for previous TCC locations. 

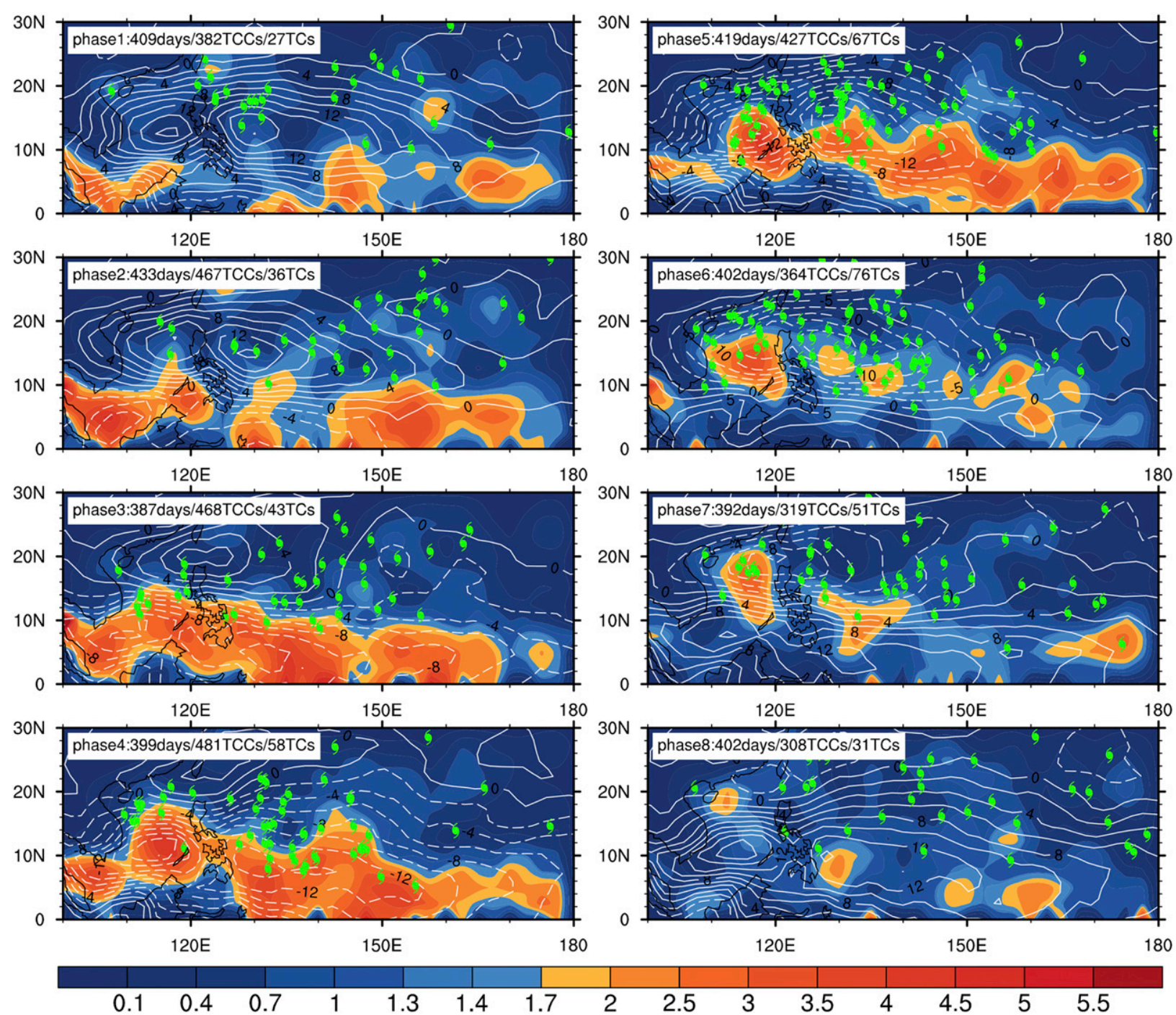

FIG. 2. Composite of OLR anomalies (contours) for different ISO phases from May to October for the period 1982-2009 together with TC locations (typhoon symbols) and distribution of TCCs (shading) over the WNP basin. Strong ISO days, TCC counts, and TC counts during each ISO phase are plotted in the upper-left corner of each panel.

Following Hennon et al. (2013), TCCGP is computed as the percentage of TCCs that develop into TCs, with the following expression:

$$
\mathrm{TCCGP}=\frac{\mathrm{TC}(\mathrm{IBTrACS})}{\mathrm{TCC}(\text { total })} \times 100 \%
$$

where TC(IBTrACS) is the total TC count in the IBTrACS dataset for the period and area of interest, and TCC(total) is the total TCC counts for the same parameters. With these definitions, the average TCCGP in the WNP basin is $\sim 13.6 \%$ (5002 TCCs and 682 TCs) during the extended boreal summer over the period 1982-2009, consistent with the results obtained in Hennon et al. (2013).

\section{b. Identification of the boreal summer ISO mode over the WNP basin}

EOF analysis (Weare and Nasstrom 1982) is used in this study to extract the ISO mode, as has been done in previous studies (Kim et al. 2008; Jiang and Waliser 2008, 2009; Huang et al. 2011; Jiang et al. 2012a,b; Li and Zhou 2013a; Zhao et al. 2015a,b, 2018c; Neena et al. 2017). EOF analysis of the daily 30-60-day bandpassfiltered OLR anomalies during the extended boreal summer for the period 1982-2009 is performed here over the domain extending over $0^{\circ}-30^{\circ} \mathrm{N}, 100^{\circ} \mathrm{E}-180^{\circ}$, instead of adopting the $15^{\circ} \mathrm{S}-15^{\circ} \mathrm{N}$ band used in Wheeler and Hendon (2004). The selection of this particular EOF domain is mainly due to the more vigorous convective 
activity over the WNP basin during the extended boreal summer (Hsu et al. 2004; Zhao et al. 2015a,b). The extended boreal summer ISO mode over the WNP basin is identified by the first two leading EOF modes (i.e., EOF-1 and EOF-2; Fig. 1). Based on the formula proposed by North et al. (1982), the first two EOFs are well separated from each other, and the first two EOFs stand out from the remaining EOF modes (figure not shown). The first two EOFs contribute about 33\% of the total anomalous variance of the 30-60-day bandpassfiltered daily data (Fig. 1), which is consistent with results in previous studies (Li and Zhou 2013a; Zhao et al. 2015a,b). Further spectral analysis of the time series of the principal components (PCs) of EOF-1 and EOF-2 suggests a peak period of about 40 days (figure not shown). These features are generally consistent with previous studies (Kim et al. 2008; Huang et al. 2011; Lee et al. 2013; Li and Zhou 2013a; Zhao et al. 2015a,b). In summary, the first two leading EOFs capture the extended boreal summer ISO mode over the WNP basin.

Following Wheeler and Hendon (2004), the first two PCs are used to determine daily ISO amplitudes and phases, ranging from phases 1 to 8 . Once the eight phases are obtained, each available day is assigned into one of these eight phases. Composite maps of observed OLR and other variables are obtained by averaging the 30-60-day bandpass-filtered anomalies of OLR and other variables over each ISO phase, based on selected strong ISO events during the extended boreal summer for the period 1982-2009. A strong ISO event is defined as $\sqrt{\mathrm{PC}^{2}+\mathrm{PC}^{2}} \geq 1.0$. The TC and TCC data are then binned into one of these eight phases. Each TC or each TCC is assigned to a specific phase of the ISO mode based on the day of TC and TCC formation. The anomalies are calculated as deviations from the ISO phase 1-8 average when the ISO amplitude is greater than one.

\section{c. Diagnostic tool of the role of environmental factors}

The GPI is used to assess the relative role of the largescale environmental factors affecting WNP TCCGP. We use the GPI for two main reasons. One is that the GPI associated with the ISO mode can capture well the significant difference of TCCGP over the WNP basin between the convectively active and inactive ISO phases. The other is that the difference field of the GPI anomaly between the two ISO phases has a larger correlation with the difference of the TCCGP anomaly between the two ISO phases (pattern correlation coefficient is 0.63 ) than that with the difference of TCs or TCCs (pattern correlation coefficient is 0.44 and 0.27 , respectively). A pattern correlation of 0.6 represents a reasonable lower limit for statistical significance, as suggested by Wilks (2006). In this sense, the GPI is an appropriate diagnostic
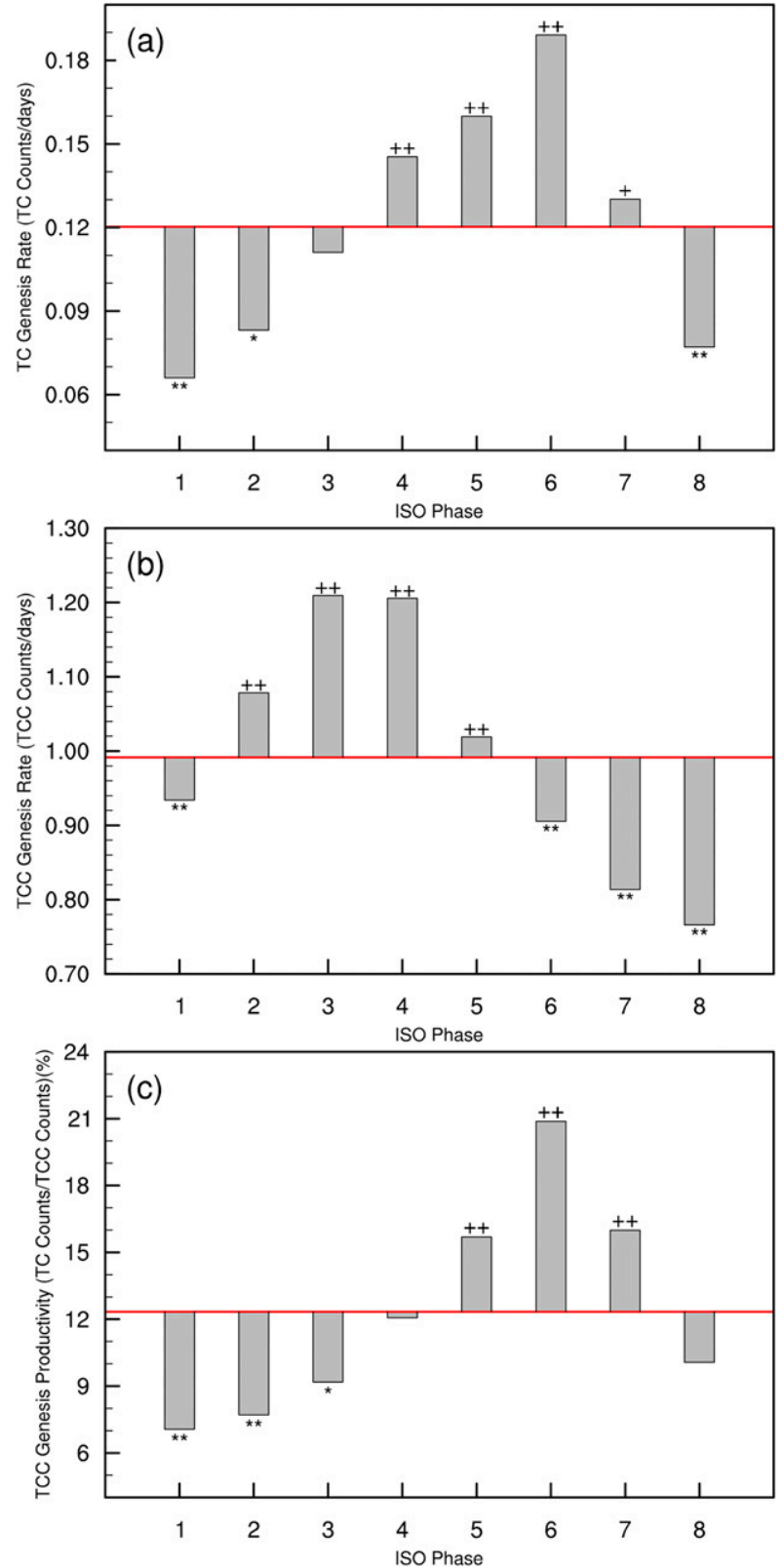

FIG. 3. (a) TC DGR, (b) TCC DRG, and (c) TCCGP over the WNP basin for all ISO phases from May to October for the period 1982-2009. The symbols "**" and "**" ("++" and "+") indicate that the DGR is statistically significant from the 8-phase average at the $95 \%$ and $90 \%$ confidence level, respectively. The corresponding 8-phase average is plotted with red lines.

tool for TCCGP. The GPI from Emanuel and Nolan (2004) is adopted in this study using the following expression:

$$
\begin{aligned}
\mathrm{GPI}= & \left|10^{5} \xi\right|^{3 / 2} \times\left(\frac{H}{50}\right)^{3} \times\left(\frac{V_{\mathrm{pot}}}{70}\right)^{3} \\
& \times\left(1+0.1 \times V_{\text {shear }}\right)^{-2}
\end{aligned}
$$


where $\xi$ represents the absolute vorticity $\left(\mathrm{s}^{-1}\right)$ at $850 \mathrm{hPa}$, $H$ represents the relative humidity $(\%)$ at $600 \mathrm{hPa}$, and $V_{\text {pot }}$ represents the potential intensity $\left(\mathrm{PI} ; \mathrm{m} \mathrm{s}^{-1}\right.$ ) that provides a theoretical upper bound on TC intensity under given specific environmental thermodynamic conditions. Details on the PI computation can be found in Bister and Emanuel (2002), who consider SST and vertical profiles of temperature and specific humidity in the troposphere as defined in the following expression:

$$
V_{\mathrm{pot}}^{2}=\frac{T_{s}}{T_{o}} \frac{C_{k}}{C_{D}}\left(\mathrm{CAPE}^{*}-\mathrm{CAPE}^{b}\right),
$$

where $T_{s}$ is SST, $T_{o}$ is the mean outflow temperature at the level of neutral buoyancy, $C_{k}$ is the exchange coefficient for enthalpy, $C_{D}$ is the drag coefficient, CAPE* is the convective available potential energy (CAPE) for an air parcel at the radius of maximum winds, and $\mathrm{CAPE}^{b}$ is the CAPE of the boundary layer air (Bister and Emanuel 2002; Camargo et al. 2007). Both CAPE* and $\mathrm{CAPE}^{b}$ are calculated at the radius of maximum winds. However, CAPE* is calculated from a saturated parcel at the sea surface, whereas $\mathrm{CAPE}^{b}$ is calculated from a boundary layer parcel. The application of PI theory is discussed online (http://wind.mit.edu/ emanuel/holem/ node3.html). The code for the calculation of PI is downloaded from Emanuel's website (ftp://texmex.mit.edu/ pub/emanuel/TCMAX). The variable $V_{\text {shear }}$ is the vertical wind shear, computed as the magnitude of the vector difference between the winds at 850 and $200 \mathrm{hPa}\left(\mathrm{m} \mathrm{s}^{-1}\right)$.
The GPI can be represented as shown in Eq. (2) by these four components, labeled $\eta=\left|10^{5} \xi\right|^{3 / 2}, \gamma=(H / 50)^{3}, \varphi=$ $\left(V_{\text {pot }} / 70\right)^{3}$, and $S=\left(1+0.1 \times V_{\text {shear }}\right)^{-2}$, which correspond to $850-\mathrm{hPa}$ absolute vorticity, $600-\mathrm{hPa}$ relative humidity, PI, and vertical wind shear, respectively. Studies have suggested that the GPI can capture the variability of TC genesis at various time scales including interdecadal (Zhao et al. 2018b; Hsu et al. 2014), interannual (Camargo et al. 2007; Zhao and Raga 2014), and intraseasonal (Camargo et al. 2009; Huang et al. 2011; Jiang et al. 2012a; Zhao et al. 2015a,b, 2016, 2018a; Zhao and $\mathrm{Wu}$ 2017). As has been done in previous studies on intraseasonal time scales, each of these four linear terms contributing to GPI anomalies can be decomposed into two components: a climatological annual component and an anomalous component, which contains variability on various time scales from synoptic to interannual. Similar to Camargo et al. (2009) and Jiang et al. (2012a), the respective contributions of the four environmental factors included in the GPI that are associated with the ISO are assessed. Specifically, any environmental variable can be partitioned into a climatological annual cycle component $\bar{X}$ and its fluctuation $X^{\prime}$, which contains variability on synoptic, intraseasonal, and interannual time scales (i.e., $X=$ $\bar{X}+X^{\prime}$ ), where $X$ represents each of the four GPI components in Eq. (2): $\eta, \gamma, \varphi$, and $S$. Then the GPI anomaly associated with the ISO $\left(\mathrm{GPI}^{\text {iso }}\right)$ can be expressed in terms of the four GPI components as follows:

$$
\begin{aligned}
\mathrm{GPI}^{\text {iso }}= & \bar{\gamma} \bar{\varphi} \bar{s} \eta^{\text {iso }}+\bar{\eta} \bar{\varphi} \bar{s} \gamma^{\text {iso }}+\bar{\eta} \bar{\gamma} \bar{s} \varphi^{\text {iso }}+\bar{\eta} \bar{\gamma} \bar{\varphi} s^{\text {iso }}+\left[\bar{\gamma} \bar{\varphi}\left(s^{\prime} \eta^{\prime}\right)^{\text {iso }}+\bar{\gamma} \bar{s}\left(\varphi^{\prime} \eta^{\prime}\right)^{\text {iso }}+\bar{\gamma} \bar{\eta}\left(\varphi^{\prime} s^{\prime}\right)^{\text {iso }}+\bar{\varphi} \bar{s}\left(\gamma^{\prime} \eta^{\prime}\right)^{\text {iso }}\right. \\
& \left.+\bar{\varphi} \bar{\eta}\left(\gamma^{\prime} s^{\prime}\right)^{\text {iso }}+\bar{s} \bar{\eta}\left(\gamma^{\prime} \varphi^{\prime}\right)^{\text {iso }}+\bar{\gamma}\left(\varphi^{\prime} s^{\prime} \eta^{\prime}\right)^{\text {iso }}+\bar{\varphi}\left(\lambda^{\prime} s^{\prime} \eta^{\prime}\right)^{\text {iso }}+\bar{s}\left(\gamma^{\prime} \varphi^{\prime} \eta^{\prime}\right)^{\text {iso }}+\eta\left(\gamma^{\prime} \varphi^{\prime} s^{\prime}\right)^{\text {iso }}+\left(\varphi^{\prime} s^{\prime} \eta^{\prime}\right)^{\text {iso }}\right]
\end{aligned}
$$

The total GPI anomalies associated with the ISO therefore can be decomposed into the sum of the role of the nonlinear terms and the four linear terms. Moreover, the contributions of the nonlinear terms are examined by the terms that include high-order variances of two or more of the four factors [a total of 11 terms included within the brackets in Eq. (4)]. Consequently, the GPI anomalies associated with the ISO can be written as the sum of 15 terms. The relative roles of the four linear terms can be further explored by specifying one term with its corresponding anomaly while the other three terms are specified with their summer mean climatological values. The sum of the total remaining 11 terms, including higher-order variance of 2 or more terms of the four variables is used to evaluate contributions by nonlinear terms.

\section{d. Quantification of TC activity}

Statistically significant differences in TCs, TCCs, TCCGP, and all large-scale factors at the 5\% level are calculated using a 10000-member bootstrap resampling technique (Efron 1979), as adopted in previous studies (Klotzbach and Oliver 2015; Chen and Chou 2014). The number of days that the ISO was greater than one for each ISO index phase is selected randomly with replacement from the full sample 1000 times, and anomalies with a magnitude that occurs fewer than $5 \%$ of the time in the random sample are considered to be statistically significant. The daily genesis rate (DGR), which is defined as the number of TCs divided by the number of days for a particular ISO phase, is used to quantify TC frequency. An additional statistical test was performed assuming TC 
TABLE 1. Statistics of TC counts, TCC counts, and TCCGP during the convectively active and inactive ISO phases for different regions, the differences between the two phases (normalized by strong ISO days), and the corresponding $P$ values. Values in bold indicate that the differences are significant at the $95 \%$ confidence level.

\begin{tabular}{|c|c|c|c|}
\hline \multirow[b]{2}{*}{ Regions } & Convectively active phase & Convectively inactive phase & \multirow{2}{*}{$\frac{\text { Difference of TC, TCC, TCCGP }}{P \text { value }}$} \\
\hline & \multicolumn{2}{|c|}{ TC, TCC, TCCGP } & \\
\hline $100^{\circ} \mathrm{E}-180^{\circ}, 0^{\circ}-30^{\circ} \mathrm{N}$ & $248,1591,15.6 \%$ & $134,1625,8.3 \%$ & $\mathbf{0 . 0 0 5}, 0.934, \mathbf{0 . 0 1 0}$ \\
\hline $100^{\circ} \mathrm{E}-180^{\circ}, 0^{\circ}-8^{\circ} \mathrm{N}$ & $8,553,1.55 \%$ & $0,725,0.0 \%$ & $0.123,0.313, \mathbf{0 . 0 5 1}$ \\
\hline $100^{\circ} \mathrm{E}-180^{\circ}, 8^{\circ}-22^{\circ} \mathrm{N}$ & $203,880,23.1 \%$ & $104,713,14.6 \%$ & $\mathbf{0 . 0 0 8}, 0.086, \mathbf{0 . 0 0 5}$ \\
\hline $100^{\circ} \mathrm{E}-180^{\circ}, 22^{\circ}-30^{\circ} \mathrm{N}$ & $37,158,23.4 \%$ & $30,187,16.0 \%$ & $0.532,0.338,0.255$ \\
\hline $110^{\circ}-150^{\circ} \mathrm{E}, 8^{\circ}-22^{\circ} \mathrm{N}$ & $169,572,29.6 \%$ & $71,404,17.6 \%$ & $0.007,0.033,0.009$ \\
\hline
\end{tabular}

frequency is uniform among ISO phases as the null hypothesis, following previous studies (Hall et al. 2001; Kim et al. 2008; Klotzbach 2010; Li and Zhou 2013a; Zhao and Wu 2017; Zhao et al. 2018a). A statistical parameter $Z$ is defined as

$$
Z=\frac{P-P_{e}}{\sqrt{P_{e}\left(1-P_{e}\right) / N}},
$$

where $P_{e}$ represents the climatological value of the DGR, while $P$ is the DGR, and $N$ is the number of days in a particular ISO phase. With this definition, the parameter $Z$ follows a Gaussian distribution, and the critical values for the test are $Z= \pm 1.65$ ( \pm 1.96$)$, or the $90 \%$ (95\%) confidence level, respectively. As suggested by Klotzbach and Oliver (2015), the bootstrap resampling test generally seems to be a stricter requirement than the Hall et al. (2001) test. We also performed the significance test as in Hall et al. (2001) and found almost identical results to those using the bootstrap resampling test. Therefore, significance is only displayed in this study if the particular metric investigated passed the bootstrap resampling test.

\section{Impact of the ISO on TCs, TCCs, and TCCGP}

Figure 2 illustrates the observed OLR anomaly composites along with TC genesis and TCCs during a life cycle of the ISO mode. Over the extended boreal summer, the ISO mode propagates both eastward and northward and shows strong modulation of both TCCs and TCs over the WNP basin, consistent with previous studies (Kim et al. 2008; Huang et al. 2011; Li and Zhou 2013a; Zhao et al. 2015a,b). Generally, more frequent TCs are observed during the convectively active ISO phases (phases 4-7), which are associated with negative OLR anomalies. Fewer TCs are observed during the suppressed convective ISO period (phases 1-3 and 8) and are associated with positive OLR anomalies. Such a strong modulation of ISO on TC frequency over the WNP is further seen in Fig. 3a in terms of the DGR. Lower DGR is observed during phases 1-3 and 8 , with a significant reduction occurring in phase 2 (at a 90\% confidence level) and phases 8 and 1 (at a 95\% confidence level). Higher DGR is observed during phases $4-7$, with a significant increase occurring during phases 4-6 (at a 95\% confidence level) and phase 7 (at a $90 \%$ confidence level). Also shown in Fig. 2 is a strong modulation of TCCs by the ISO with enhanced TCCs in phases 2-5 and suppressed TCCs in phases 6-8 and 1 , which is somewhat different from the ISO-driven modulation of TCs (Fig. 3). The differences in TCC and TC modulation by the boreal summer ISO phase are clearly seen in Figs. 3a and 3b. This also partly suggests that the associated physical mechanisms driving TCC formation and TC formation are not the same. Some studies have indicated differential impacts of vertical wind shear on TCCs and TCs (Zehr 1992; Gray 1998; Kerns and Zipser 2009), with TCC formation needing stronger vertical wind shear and TCs requiring weaker vertical wind shear. The underlying mechanisms responsible for TC genesis versus TCC formation deserve further investigation.

TCCGP is largely determined by changes in the number of TCCs and TCs. Although there are distinct ISO modulations of TCC and TCs, Fig. $3 \mathrm{c}$ indicates a strong modulation of TCCGP, which is similar to the modulation of TCs. Lower TCCGP is observed during convectively inactive ISO phases $1-3$ and 8 , with a significant reduction occurring in phases 1 and 2 (at a $95 \%$ confidence level) and 3 (at a $90 \%$ confidence level). Higher TCCGP is observed during convectively active ISO phases $4-7$, with a significant increase at a $95 \%$ confidence level occurring during phases 5-7. To further highlight these observed differences and ensure a large enough sample size, we combine phases $1-3$ and 8 into one category named the convectively inactive ISO phase and phases 4-7 into another category named the convectively active ISO phase.

Since there is the possibility of differential modulations of the spatial distribution of TCCs and TCs and thus on TCCGP over the WNP basin by the ISO mode, statistics of TCCs, TCs, and TCCGP over different subregions are computed (Table 1). Significant differences (at a $95 \%$ 


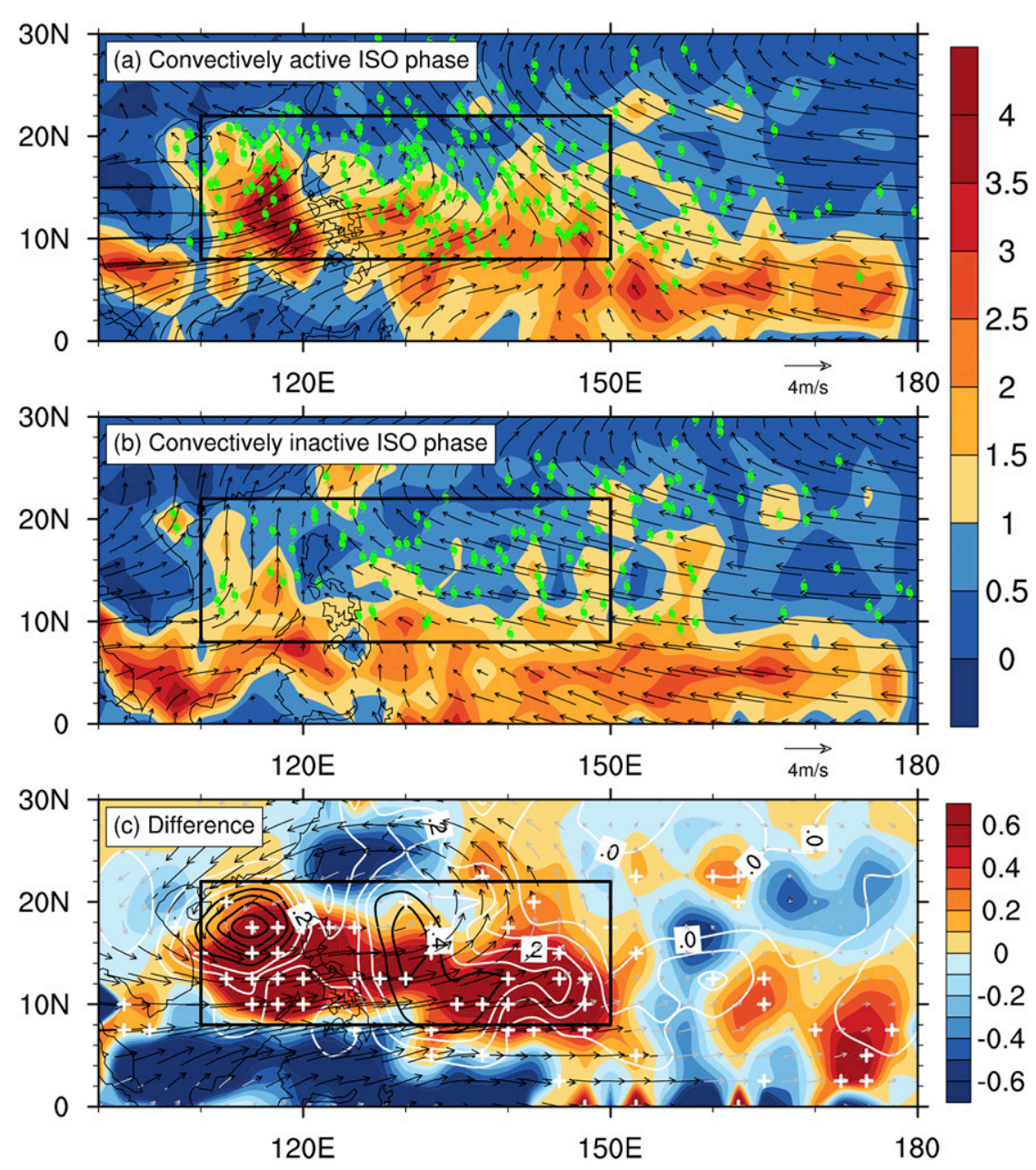

FIG. 4. Composite of 850-hPa total wind (vectors) and distribution of TCCs (shading) over the WNP basin during the convectively (a) active and (b) inactive ISO phases and (c) differences of 850-hPa wind vectors together with differences of TCCs (shading) and TC genesis frequency (contours) between the convectively active and inactive ISO phases. The rectangular box $\left(8^{\circ}-22^{\circ} \mathrm{N}, 110^{\circ}-150^{\circ} \mathrm{E}\right)$ indicates the main $\mathrm{TC}$ formation region as well as the MDR for TCCs. Typhoon symbols correspond to the initial TC location. The symbol "+" (wind vectors in black) indicates that the difference in TCCs (850-hPa total wind field) is statistically significant between the convectively active and inactive ISO phases at the $95 \%$ confidence level.

confidence level) of TC counts and TCCGP normalized by ISO days between the two ISO phases are found over the whole WNP basin $\left(0^{\circ}-30^{\circ} \mathrm{N}, 100^{\circ} \mathrm{E}-180^{\circ}\right)$, while observed differences of TCCs are not statistically significant at a $95 \%$ confidence level. Similar results are found for the subregion $8^{\circ}-22^{\circ} \mathrm{N}, 100^{\circ} \mathrm{E}-180^{\circ}$ with significant differences in both TCs and TCCGP between convectively active and inactive ISO phases, while there is no significant difference in TCCs between convectively active and inactive ISO phases. In contrast, over the other two subregions, $0^{\circ}-8^{\circ} \mathrm{N}, 100^{\circ} \mathrm{E}-180^{\circ}$ and $22^{\circ}-30^{\circ} \mathrm{N}, 100^{\circ} \mathrm{E}-$ $180^{\circ}$, no significant differences are found for TCCs, TCs, or TCCGP, except for a significant difference of TCCGP over $0^{\circ}-8^{\circ} \mathrm{N}, 100^{\circ} \mathrm{E}-180^{\circ}$. These results suggest that the ISO modulation of TCCs, TCs, and TCCGP is mostly felt over the subregion defined as $8^{\circ}-22^{\circ} \mathrm{N}, 100^{\circ} \mathrm{E}-180^{\circ}$. Further analyses indicate that the differences of TCCs and TCs over the subregion $8^{\circ}-22^{\circ} \mathrm{N}, 100^{\circ} \mathrm{E}-180^{\circ}$ between the convectively active and inactive ISO phases are mainly related to changes of TCCs over the main development region (MDR) $\left(8^{\circ}-22^{\circ} \mathrm{N}, 110^{\circ}-150^{\circ} \mathrm{E}\right)($ Table 1$)$. Notably, TCCs, TCs, and TCCGP over the MDR of the WNP basin show almost identical changes in response to the phase changes of the ISO mode, with more TCCs and TCs and enhanced TCCGP during the convectively active ISO phase and fewer TCCs and TCs and decreased 

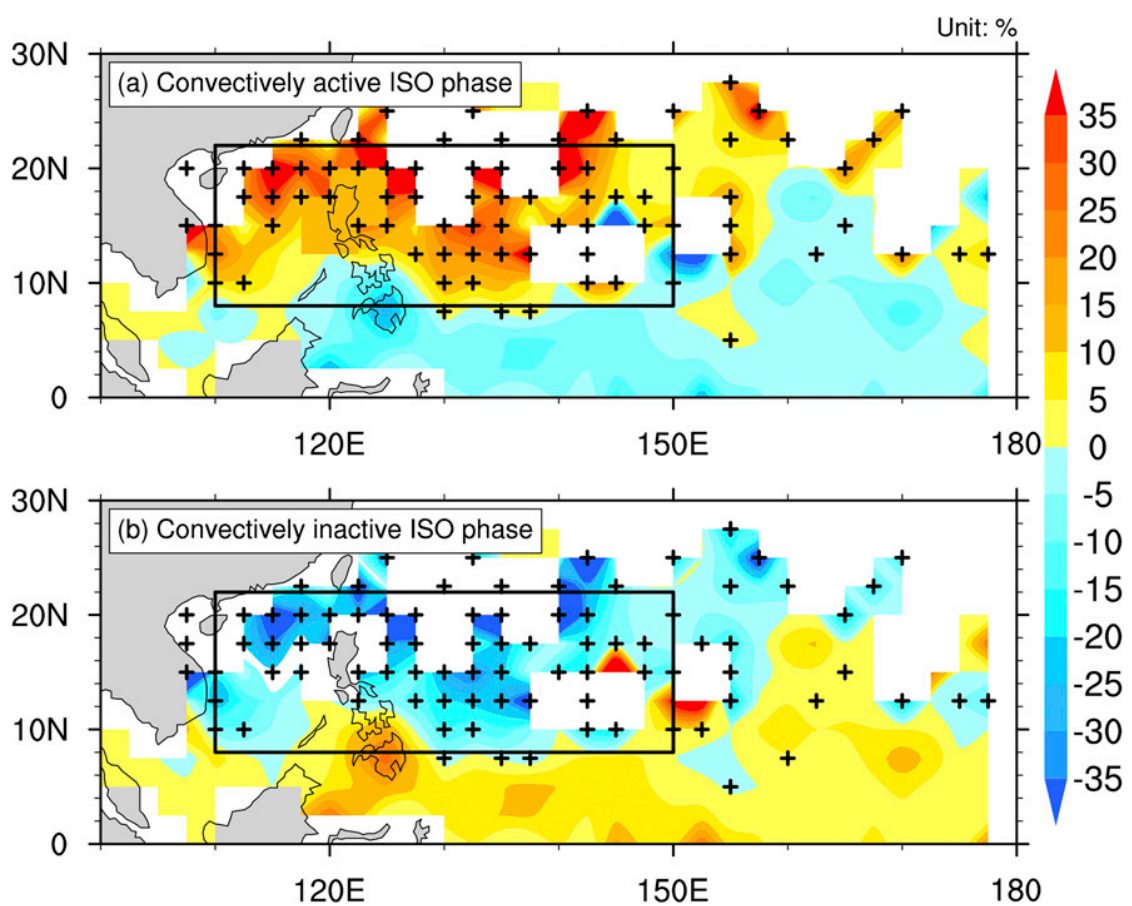

FIG. 5. Composite anomalies of TCCGP (\%) over the WNP basin for the convectively (a) active and (b) inactive ISO phases. The rectangular box $\left(8^{\circ}-22^{\circ} \mathrm{N}, 110^{\circ}-150^{\circ} \mathrm{E}\right)$ indicates the main TC region as well as the MDR for TCCs. The white shaded areas represent the grid points where the number of TCCs is zero. The symbol "+" indicates that the difference of TCCGP is statistically significant between the convectively active and inactive ISO phases at the $95 \%$ confidence level.

TCCGP during the convectively inactive ISO phase. The remainder of this manuscript focuses on the MDR of the WNP basin unless otherwise noted.

\section{Importance of large-scale factors affecting TC genesis}

Figure 4 displays the composite of total 850-hPa winds during the convectively active ISO phase and convectively inactive ISO phase as well as their differences. Also plotted are TCCs and TCs forming during both ISO phases. Note the stronger large-scale low-level circulation over the WNP basin and the broad extent of the monsoon trough during the convectively active ISO phase (Fig. 4a), while a weaker monsoon circulation associated with a weakened monsoon trough is found during the convectively inactive ISO phase (Fig. 4b). In response to the change of the large-scale monsoon circulation over the WNP basin, TCCs and TCs show a corresponding change with more (fewer) TCCs and TCs over the MDR of the WNP basin, displayed in Fig. 4c. A maximum in positive anomalies of the differences of the spatial distribution in TCCs and TCs between the convectively active and inactive ISO phases can be observed over the MDR with a well-defined cyclonic circulation anomaly over the monsoon trough region. Correspondingly, the spatial distribution of TCCGP anomalies calculated from the ISO phase 1-8 average shows a similar change associated with the ISO mode (Fig. 5). The value of TCCGP in Fig. 5 is calculated as the ratio of total TC counts to total TCC counts at each $2.5^{\circ} \times 2.5^{\circ}$ grid during the convectively active and inactive ISO phases, respectively. Consistent with the results in Table 1 showing a significant difference in TCCGP between the convectively active and inactive ISO phases, significant positive TCCGP anomalies are found over the MDR during the convectively active ISO phase (Fig. 5a), with significant negative TCCGP anomalies found during the convectively inactive ISO phase (Fig. 5b). Furthermore, the changes in the low-level monsoon circulation are possibly closely associated with the ISO mode. This can be partly inferred from the composite of 30-60-day filtered 850-hPa relative vorticity anomalies (Fig. 6). Enhanced relative vorticity during the convectively active ISO phase and decreased relative vorticity over the MDR during the convectively inactive ISO phase are observed. Moreover, our analyses show that the difference of the averaged $850-\mathrm{hPa}$ relative vorticity anomalies associated 
(a) Convectively active ISO phase

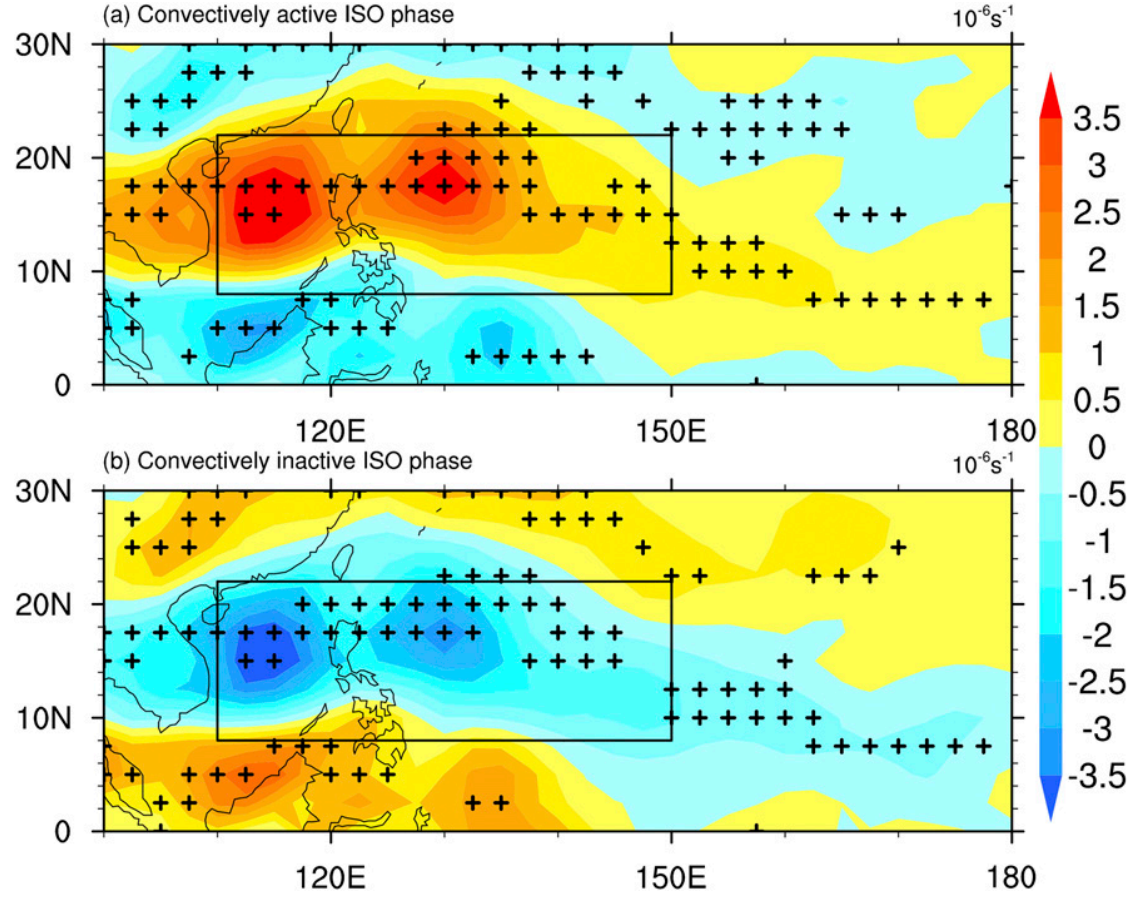

FIG. 6. Composite of 30-60-day filtered 850-hPa relative vorticity anomalies $\left(10^{-6} \mathrm{~s}^{-1}\right)$ over the WNP basin from May to October for the period 1982-2009 for (a) convectively active and (b) convectively inactive ISO phases. The rectangular box $\left(8^{\circ}-22^{\circ} \mathrm{N}, 110^{\circ}-150^{\circ} \mathrm{E}\right)$ indicates the main TC region as well as the MDR for TCCs. The symbol "+ " indicates that the difference of $850-\mathrm{hPa}$ relative vorticity is statistically significant between the convectively active and inactive ISO phases at the $95 \%$ confidence level.

with the ISO mode over the MDR between the convectively active and inactive ISO phases are significant at a $95 \%$ confidence level (Table 2). This implies that the changes in the low-level circulation, especially changes in the monsoon trough region, associated with the ISO mode play a role in affecting TCCs and TCs and thus TCCGP over the monsoon trough region.

Positive midlevel relative humidity anomalies over the MDR are seen during the convectively active ISO phase, while negative anomalies are present during the convectively inactive ISO phase (Fig. 7; shading), in response to more TCCs, TCs, and TCCGP. The change of midlevel relative humidity between the convectively active and inactive ISO phases appears to be a positive contributor to increased TCCs, TCs, and TCCGP during the convectively active ISO phase. In contrast, negative vertical wind shear anomalies during the convectively inactive ISO phase and positive vertical wind shear anomalies during the convectively active ISO phase (Fig. 7; contour) appear to negatively impact the frequency of TCs and TCCs and the value of TCCGP. The increased vertical wind shear anomaly over the WNP during the convectively active ISO phase is consistent with the low-level westerly anomaly that is observed. Table 2 summarizes these differences, showing that the difference of the averaged $600-\mathrm{hPa}$ relative humidity

TABLE 2. Statistics of anomalous large-scale factors including OLR, vertical wind shear, 600-hPa relative humidity, and 850-hPa relative vorticity associated with the ISO mode over the MDR $\left(110^{\circ}-150^{\circ} \mathrm{E}, 8^{\circ}-22^{\circ} \mathrm{N}\right)$ during the convectively active and inactive ISO phases, their differences, and correlation coefficients with the TCCGP. Differences and correlation coefficients in bold are significant at the $95 \%$ confidence level.

\begin{tabular}{lccrr}
\hline \hline & OLR $\left(\mathrm{W} \mathrm{m}^{-2}\right)$ & $\begin{array}{c}\text { Vertical wind } \\
\text { shear }\left(\mathrm{m} \mathrm{s}^{-1}\right)\end{array}$ & $\begin{array}{c}\text { 600-hPa relative } \\
\text { humidity }(\%)\end{array}$ & $\begin{array}{c}850-\mathrm{hPa} \text { relative } \\
\text { vorticity }\left(10^{-6} \mathrm{~s}^{-1}\right)\end{array}$ \\
\hline Convectively active ISO phase & -7.6 & 0.05 & 1.4 & 1.6 \\
Convectively inactive ISO phase & 6.6 & -0.05 & -1.3 & -1.5 \\
Difference & $\mathbf{- 1 4 . 2}$ & 0.10 & $\mathbf{2 . 7}$ & $\mathbf{3 . 1}$ \\
Correlation coefficient with TCCGP & $\mathbf{- 0 . 8 1}$ & 0.53 & $\mathbf{0 . 7 9}$ & $\mathbf{0 . 8 0}$ \\
\hline
\end{tabular}


(a) Convectively active ISO phase $\%($ Shaded); $\mathrm{m} / \mathrm{s}$ (Contour)

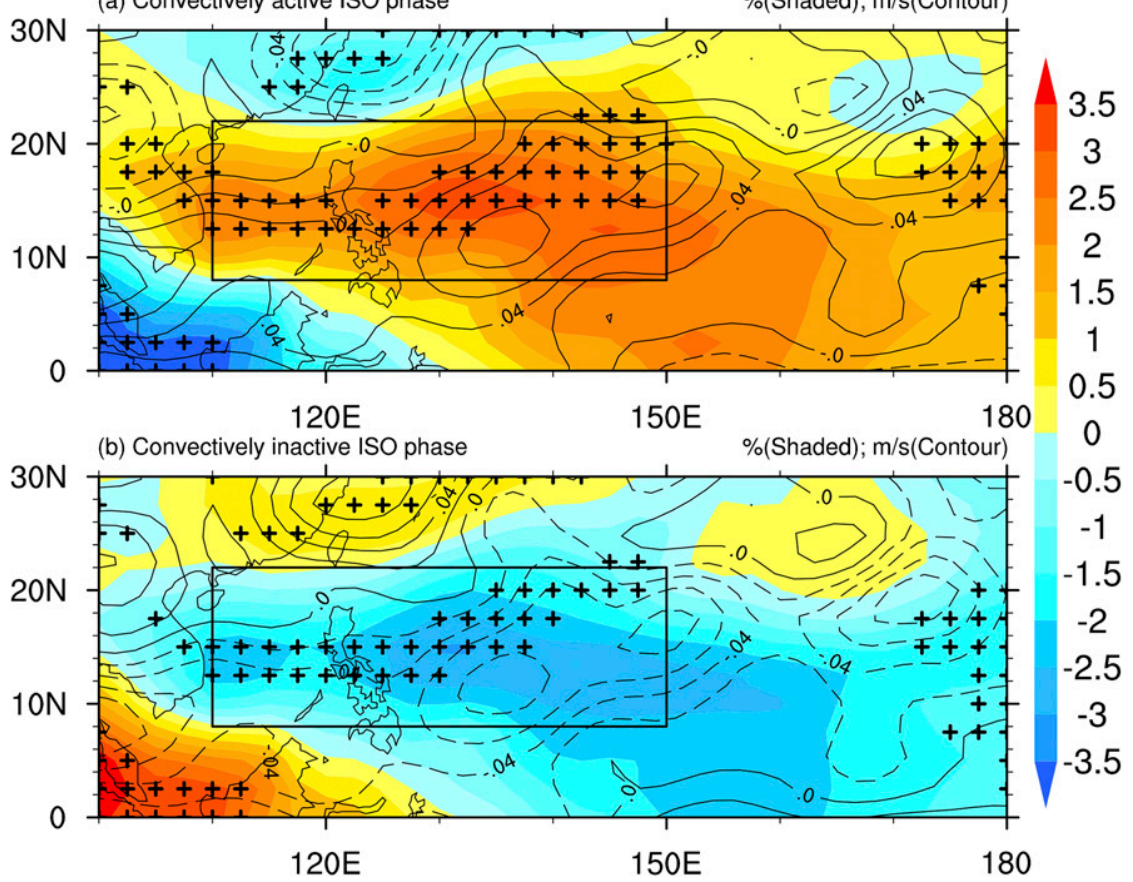

FIG. 7. Composite of 30-60-day filtered 600-hPa relative humidity anomalies (\%; shading) and vertical wind shear anomalies ( $\mathrm{m} \mathrm{s}^{-1}$; contours) over the WNP basin for the (a) convectively active and (b) convectively inactive ISO phases from May to October for the period $1982-2009$. The rectangular box $\left(8^{\circ}-22^{\circ} \mathrm{N}, 110^{\circ}-150^{\circ} \mathrm{E}\right)$ indicates the main $\mathrm{TC}$ region as well as the MDR for TCCs. The symbol " " " indicates that the difference of 600-hPa relative humidity is statistically significant between the convectively active and inactive ISO phases at the $95 \%$ confidence level.

anomalies associated with the ISO mode over the MDR between the convectively active and inactive ISO phases is significant at a $95 \%$ confidence level, while the difference of vertical wind shear anomalies associated with the ISO mode is not statistically significant at a $95 \%$ confidence level. Consequently, one would expect that the role of the changes of midlevel relative humidity associated with the ISO mode would be more important than the role of vertical wind shear. The relative importance of these large-scale factors is further confirmed by their correlations with TCCGP (Table 2). TCCGP has a significant correlation with each of the four factors except for the vertical wind shear.

Following the approach adopted in previous studies (Jiang et al. 2012a; Zhao et al. 2015a,b), a budget analysis of the GPI is used to explore the relative importance of large-scale factors. Details on the analysis of GPI are described in section 2c. The GPI anomalies associated with the ISO are shown in Fig. 8. GPI anomalies associated with the ISO mode depict well the intraseasonal modulation on TCCGP by the ISO mode. As seen in Figs. 5 and 8, positive TCCGP occurs over regions with positive GPI anomalies during the convectively active
ISO phase, and negative TCCGP agrees well with negative GPI anomalies during the convectively inactive ISO phase. Such a close connection between the ISO and GPI anomaly and TCCGP are further confirmed by conducting a correlation analysis of the eight ISO phases. The correlation between the ISO index and TCCGP (GPI) is $0.77(0.83)$, which is significant at a $95 \%$ confidence level. In summary, the GPI anomalies demonstrate considerable skill in capturing TCCGP over the WNP basin associated with the ISO mode. These findings increase our confidence to examine the respective role of each of the factors included in the GPI in contributing to the TCCGP associated with the ISO.

The contributions of the four environmental factors to the magnitude of the GPI anomalies as a function of the ISO phase are computed for the MDR (Table 3). The changes of GPI anomalies associated with the ISO mode are the combined effects of changes in large-scale factors and nonlinear terms affected by the ISO mode. Low-level relative vorticity is the largest positive contributor to the GPI anomalies, and the second largest positive contributor is the midlevel relative humidity. Both vertical wind 


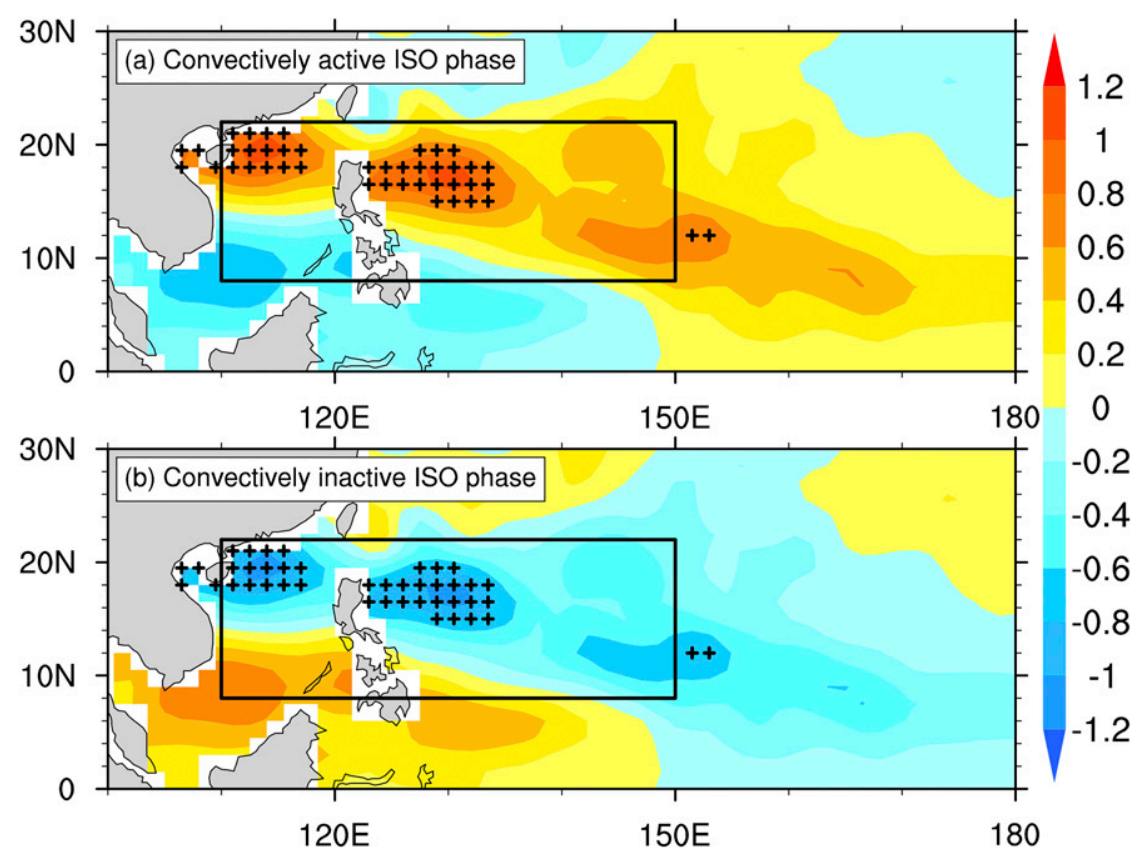

FIG. 8. Composite of 30-60-day filtered GPI anomalies over the WNP basin for the (a) convectively active and (b) inactive ISO phases varying all four variables (GPI-TOTAL). The rectangular box $\left(8^{\circ}-22^{\circ} \mathrm{N}, 110^{\circ}-150^{\circ} \mathrm{E}\right)$ indicates the main $\mathrm{TC}$ region as well as the MDR for TCCs. The symbol "+" indicates that the difference of GPI is statistically significant between the convectively active and inactive ISO phases at the $95 \%$ confidence level.

shear and PI only weakly contribute to the changes in GPI anomalies associated with ISO phase changes. The role of these large-scale factors associated with the ISO mode is consistent with the differences in large-scale factors between the convectively active and inactive ISO phases shown in Table 2 .

Note that the nonlinear terms are also important players in modulating the TCCGP between the convectively active and inactive ISO phases (Table 3 ). In terms of the definition of nonlinear terms, this implies that multiscale interactions (e.g., synoptic scale and high-frequency ISO time scales) are significantly different between the convectively active and inactive ISO phases. The changes of synoptic-scale wave activity over the WNP basin between the two different ISO phases are now further investigated. During the convectively active phases, a stronger synoptic-scale wave train activity is observed during the convectively active ISO phase with an average amplitude of 1.35 (Fig. 9a). Correspondingly, composite of cyclonic $850-\mathrm{hPa}$ wind anomalies show a rapid growth of 3-8-day low-level eddy kinetic energy (EKE; Fig. 10a). The synoptic-scale wave train pattern is obtained from the EOF analysis of 3-8-day filtered OLR anomalies following Zhao et al. (2016). In contrast, the opposite situation can be found during the convectively inactive ISO phase with decreased 3-8-day eddy kinetic energy at $850 \mathrm{hPa}$ and a weaker synoptic-scale wave train with an average amplitude of 1.08 in response to anticyclonic $850-\mathrm{hPa}$ wind anomalies (Figs. 9b, 10b). The difference in amplitude of

TABLE 3. Statistics of the averaged GPI anomalies varying all four variables (GPI-Total). Also displayed are the same as the GPI-Total but varying $850-\mathrm{hPa}$ relative vorticity (GPI-VOR), varying $600-\mathrm{hPa}$ relative humidity (GPI-RH), varying vertical wind shear (GPISHEAR), varying PI, and the composite of GPI anomalies for the nonlinear terms (GPI-Nonlinear) associated with the ISO mode over the MDR for TC activity $\left(110^{\circ}-150^{\circ} \mathrm{E}, 8^{\circ}-22^{\circ} \mathrm{N}\right)$ during the convectively active and inactive ISO phases and their differences. Differences in bold (italics) indicate significance at a $95 \%(90 \%)$ confidence level.

\begin{tabular}{lcccrrr}
\hline \hline & GPI-Total & GPI-VOR & GPI-RH & GPI-SHEAR & GPI-PI & GPI-Nonlinear \\
\hline Convectively active phase & 0.42 & 0.37 & 0.34 & -0.28 & -0.11 & 0.10 \\
Convectively inactive phase & -0.31 & -0.31 & -0.32 & 0.13 & 0.11 & -0.01 \\
Difference & $\mathbf{0 . 7 3}$ & $\mathbf{0 . 6 8}$ & $\mathbf{0 . 6 6}$ & 0.41 & 0.22 & 0.11 \\
\hline
\end{tabular}


(a) Convectively active ISO phase $(\mathrm{AMP}=1.35)$

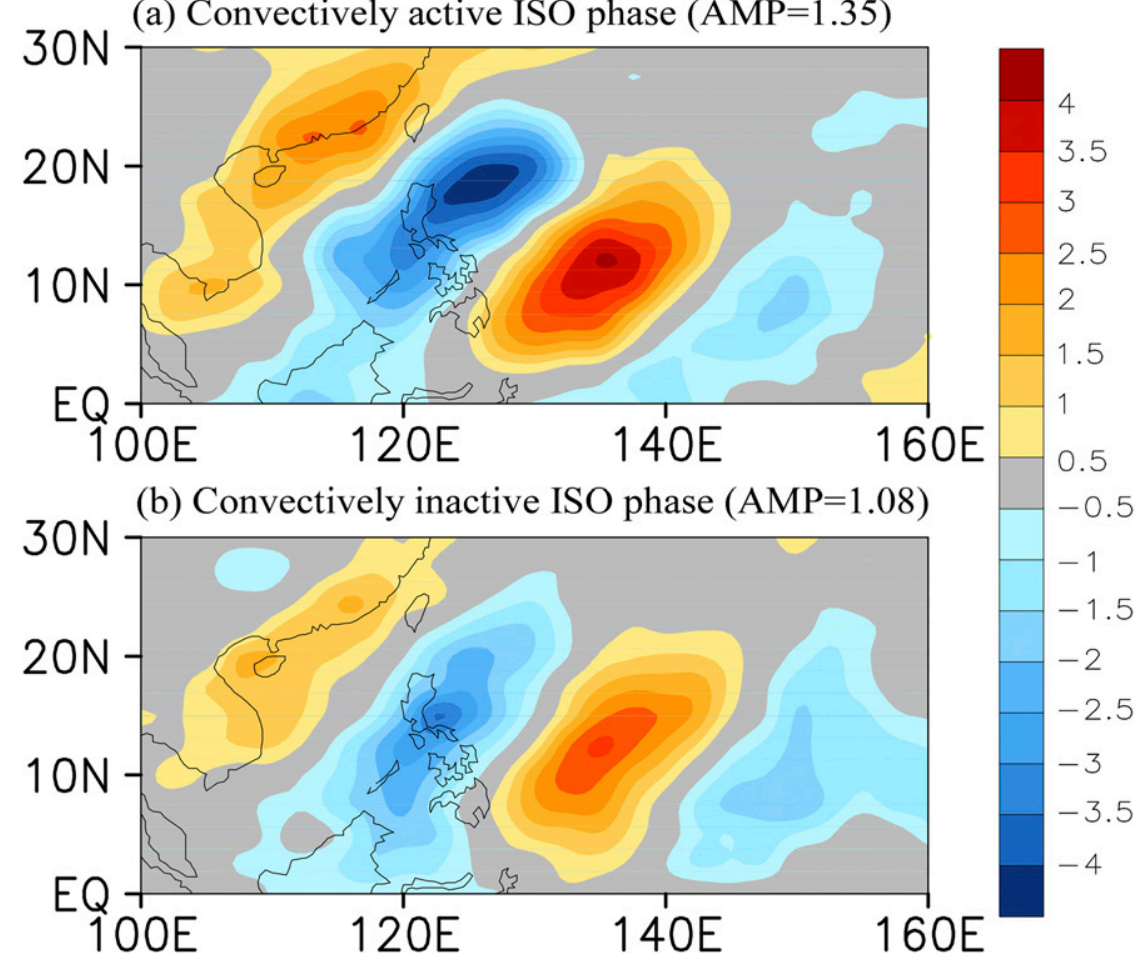

FIG. 9. Spatial patterns and amplitudes of the WNP3-8-day synoptic-scale wave train activity obtained from OLR $\left(\mathrm{W} \mathrm{m}^{-2}\right)$ for the (a) convectively active and (b) convectively inactive ISO phases.

synoptic-scale wave train activity between the convectively active and inactive ISO phases is significant at a $95 \%$ confidence level. This may partly explain the importance of nonlinear terms associated with the ISO mode. However, the details of physical mechanisms relating to multiscale interactions on intraseasonal time scales need further study.

Similar results are found in terms of pattern correlations of difference fields of GPI-Total and GPI with varying factors between the convectively active and inactive ISO phases. The pattern correlations of GPI-Total and $600-\mathrm{hPa}$ relative humidity (GPI-RH), 850-hPa relative vorticity (GPI-VOR), GPI anomalies for the nonlinear terms (GPI-Nonlinear), PI (GPI-PI), and vertical wind shear (GPI-SHEAR) are $0.65,0.64,0.61,-0.43$, and 0.31 , respectively. These suggest that the low-level relative vorticity, midlevel relative humidity, and nonlinear terms are the three most important contributors to the distribution of GPI anomalies associated with the ISO, while vertical wind shear and PI play a weaker role.

\section{Summary}

This study investigates the impact of the ISO mode on the extended boreal summer TCCGP over the WNP basin, a topic which has until now been relatively infrequently studied. Results suggest that the extended boreal summer ISO mode exerts a strong modulation on TCCGP as well as TCCs and TCs over the WNP basin, especially over the monsoon trough region. More TCCs and TCs and higher TCCGP are observed over the MDR of the WNP basin during the convectively active ISO phase compared with the convectively inactive ISO phase. This implies that the large-scale environmental factors during the convectively active ISO phase are more favorable for TCCs developing into TCs. Our results suggest that the boreal summer ISO can significantly modulate the TCCGP over the WNP basin, consistent with the results of Lin and Lee (2011). Lin and Lee (2011) emphasized the influence of a favorable synoptic environment associated with the convectively active ISO phase. More recently, using an approach different from the TCC analysis used in this study, Chen et al. (2018) implemented a vortex analysis to systematically study the impact of tropical waves including the MJO and equatorial Rossby waves on TC genesis productivity in the WNP basin. They also found a significantly higher TCCGP during the convectively active MJO phase than during the convectively inactive MJO phase. However, Liebmann et al. (1994) found that the 
(a) Convectively active ISO phase

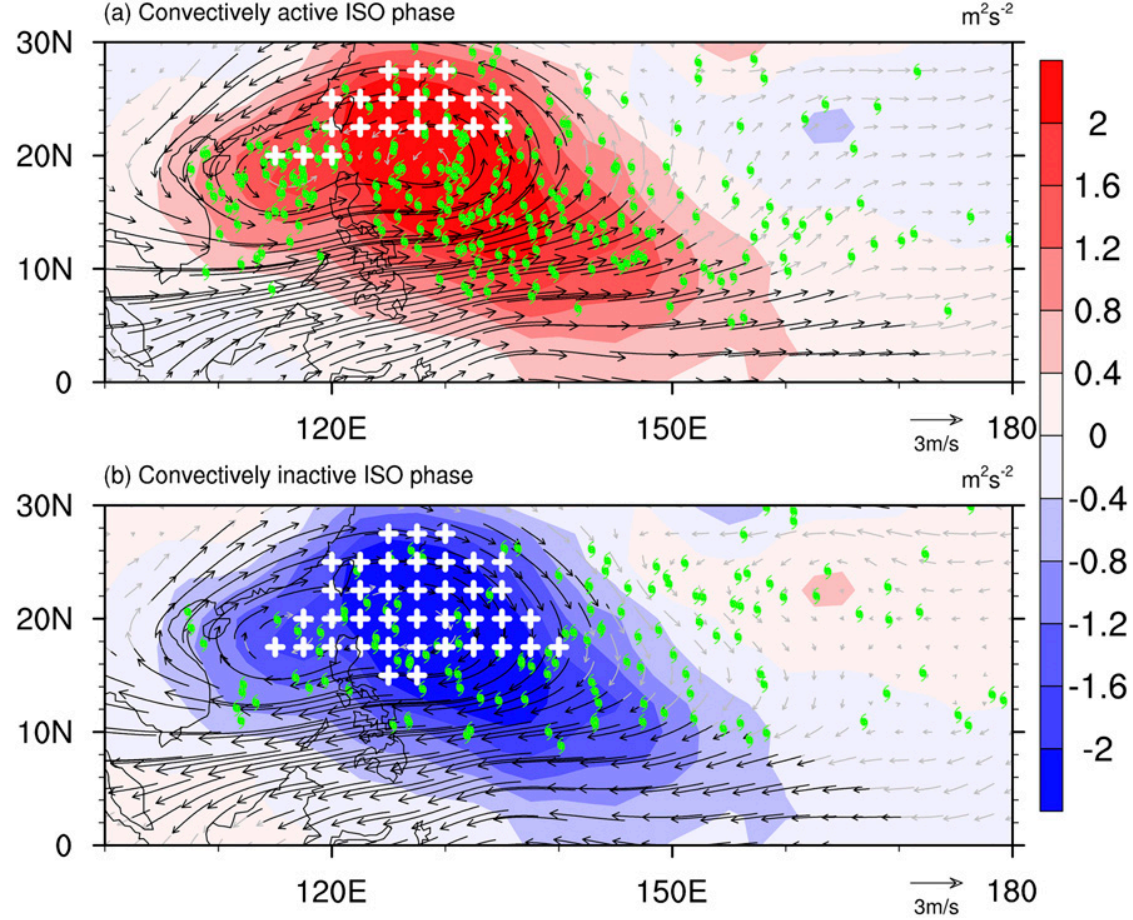

FIG. 10. Composite of 3-8-day filtered EKE anomalies $\left(\mathrm{m}^{2} \mathrm{~s}^{-2}\right.$; shading) and 30-60-day filtered wind anomalies at $850 \mathrm{hPa}$ over the WNP basin for (a) convectively active and (b) convectively inactive ISO phases. Typhoon symbols correspond to the initial TC location. The symbol "+" (wind vectors in black) indicates that the difference of EKE (30-60-day filtered $850-\mathrm{hPa}$ wind anomaly) is statistically significant between the convectively active and inactive ISO phases at the $95 \%$ confidence level. ratio of tropical storms (TS) to tropical depressions (TD) was nearly constant, indicating that the ratio of TS to TD appears to be independent of the ISO mode. Since there is a similar TS to TD ratio during the convectively active phase and the convectively inactive phase, we speculate that the strong modulation of the TCCGP by the boreal summer ISO mode may be due to the strong modulation of the ratio of TD to TCC by the ISO. These changes are accompanied by a significantly different synoptic environment as was noted in Liebmann et al. (1994). This may be partly explained by significantly different synoptic-scale wave activity between the convectively active and inactive ISO phases.

The distribution of TCCGP between the convectively active and inactive ISO phases matches well with the GPI anomalies associated with the ISO mode. During the convectively active ISO phase, positive GPI anomalies are associated with positive TCCGP anomalies. In contrast, negative GPI anomalies are associated with negative TCCGP anomalies during the convectively inactive ISO phase. Our budget analysis of GPI suggests that low-level relative vorticity and midlevel relative humidity are the two primary factors contributing to the
GPI anomalies associated with the ISO mode. A stronger low-level large-scale circulation and an extended monsoon trough over the WNP basin with increased midlevel relative humidity are found during the convectively active ISO phase. The convectively inactive ISO phase displays a near-inverse signal in terms of both the circulation direction and the anomaly sign. Consistent with no significant difference of vertical wind shear anomalies or PI anomalies over the MDR between the convectively active and inactive ISO phases, neither of these factors show significant ISO-driven modulation of GPI anomalies. The relative importance of the four environmental factors included in the GPI is also based upon the spatial distribution of their anomalies.

Notably, the nonlinear terms have contributions comparable to the vertical wind shear and PI terms. Their importance is consistent with the observed synoptic-scale wave activity and low-level EKE. During the convectively active ISO phase, there is more vigorous synoptic-scale wave train activity and an associated rapid growth of lowlevel EKE than during the convectively inactive ISO phase. Note that the role of synoptic wave activity and its contribution of GPI nonlinear terms to TCCGP is 
emphasized in this study. In fact, nonlinear contributions to observed GPI anomalies associated with the ISO mode are due to the covariance terms of the anomalies of factors included in the GPI associated with multiple time scales. For example, nonlinear contributions are important for eastern North Pacific TCs and are modulated on synoptic $(<8$ days) and high-frequency intraseasonal variability (ISV) scales (8-20 days) as indicated by Jiang et al. (2012a). This implies that the importance of nonlinear terms may evolve during the complex multiscale interaction of largescale factors including synoptic-scale and high-frequency ISO modes. The underlying mechanism driving the multiscale interaction associated with the extended boreal summer ISO mode needs further investigation.

Acknowledgments. This research was jointly supported by the National Natural Science Foundation of China (Grants 41675072, 41475091, and 41730961), the Natural Science Foundation of Jiangsu Province (Grant BK20181412), the Qinglan Project of Jiangsu Province (R2017Q01), the National Basic Research Program of China (Grant 2015CB452803), and the Priority Academic Program Development of Jiangsu Higher Education Institutions (PAPD). The authors thank the three anonymous reviewers for helpful comments that have significantly improved the manuscript.

\section{REFERENCES}

Bister, M., and K. A. Emanuel, 2002: Low frequency variability of tropical cyclone potential intensity 1 . Interannual to interdecadal variability. J. Geophys. Res., 107, 4801, https://doi.org/ 10.1029/2001JD000776.

Camargo, S. J., K. A. Emanuel, and A. H. Sobel, 2007: Use of a genesis potential index to diagnose ENSO effects on tropical cyclone genesis. J. Climate, 20, 4819-4834, https://doi.org/ 10.1175/JCLI4282.1.

—, M. C. Wheeler, and A. H. Sobel, 2009: Diagnosis of the MJO modulation of tropical cyclogenesis using an empirical index. J. Atmos. Sci., 66, 3061-3074, https://doi.org/10.1175/ 2009JAS3101.1.

Chan, J. C. L., 2005: Interannual and interdecadal variations of tropical cyclone activity over the western North Pacific. Meteor. Atmos. Phys., 89, 143-152, https://doi.org/10.1007/s00703-005-0126-y.

Chen, G., and C. Chou, 2014: Joint contribution of multiple equatorial waves to tropical cyclogenesis over the western North Pacific. Mon. Wea. Rev., 142, 79-92, https://doi.org/ 10.1175/MWR-D-13-00207.1.

Chen, J.-M., C.-H. Wu, P.-H. Chung, and C.-H. Sui, 2018: Influence of intraseasonal-interannual oscillations on tropical cyclone genesis in the western North Pacific. J. Climate, 31, 4949-4961, https://doi.org/10.1175/JCLI-D-17-0601.1.

Dee, D. P., and Coauthors, 2011: The ERA-Interim reanalysis: Configuration and performance of the data assimilation system. Quart. J. Roy. Meteor. Soc., 137, 553-597, https://doi.org/10.1002/qj.828.

Efron, B., 1979: Bootstrap methods: Another look at the jackknife. Ann. Stat., 7, 1-26, https://doi.org/10.1214/aos/1176344552.
Emanuel, K. A., and D. S. Nolan, 2004: Tropical cyclone activity and the global climate system. 26th Conf. on Hurricanes and Tropical Meteorology, Miami Beach, FL, Amer. Meteor. Soc., 10A.2, https://ams.confex.com/ams/pdfpapers/75463.pdf.

Gottschalck, J., and Coauthors, 2010: A framework for assessing operational Madden-Julian oscillation forecasts: A CLIVAR MJO working group project. Bull. Amer. Meteor. Soc., 91, 1247-1258, https://doi.org/10.1175/2010BAMS2816.1.

Gray, W. M., 1998: The formation of tropical cyclones. Meteor. Atmos. Phys., 67, 37-69, https://doi.org/10.1007/BF01277501.

Hall, J. D., A. J. Matthews, and D. J. Karoly, 2001: The modulation of tropical cyclone activity in the Australian region by the Madden-Julian oscillation. Mon. Wea. Rev., 129, 2970-2982, https://doi.org/10.1175/1520-0493(2001)129<2970: TMOTCA $>2.0 . \mathrm{CO} ; 2$.

Hennon, C. C., C. N. Helms, K. R. Knapp, and A. R. Bowen, 2011: An objective algorithm for detecting and tracking tropical cloud clusters: Implications for tropical cyclogenesis prediction. J. Atmos. Oceanic Technol., 28, 1007-1018, https:// doi.org/10.1175/2010JTECHA1522.1.

— , and Coauthors, 2013: Tropical cloud cluster climatology, variability, and genesis productivity. J. Climate, 26, 3046-3066, https://doi.org/10.1175/JCLI-D-12-00387.1.

Hsu, H.-H., C.-H. Weng, and C.-H. Wu, 2004: Contrasting characteristics between the northward and eastward propagation of the intraseasonal oscillation during the boreal summer. J. Climate, 17, 727-743, https://doi.org/10.1175/ 1520-0442(2004)017<0727:CCBTNA > 2.0.CO;2.

Hsu, P.-C., P.-S. Chu, H. Murakami, and X. Zhao, 2014: An abrupt decrease in the late-season typhoon activity over the western North Pacific. J. Climate, 27, 4296-4312, https://doi.org/ 10.1175/JCLI-D-13-00417.1.

Huang, P., C. Chou, and R. Huang, 2011: Seasonal modulation of tropical intraseasonal oscillations on tropical cyclone geneses in the western North Pacific. J. Climate, 24, 6339-6352, https:// doi.org/10.1175/2011JCLI4200.1.

Jiang, X., and D. E. Waliser, 2008: Northward propagation of the subseasonal variability over the eastern Pacific warm pool. Geophys. Res. Lett., 35, L09814, https://doi.org/10.1029/2008GL033723. , and _ 2009: Two dominant subseasonal variability modes of the eastern Pacific ITCZ. Geophys. Res. Lett., 36, L04704, https://doi.org/10.1029/2008GL036820.

_- T. Li, and B. Wang, 2004: Structures and mechanisms of the northward propagating boreal summer intraseasonal oscillation. J. Climate, 17, 1022-1039, https://doi.org/10.1175/ 1520-0442(2004)017<1022:SAMOTN > 2.0.CO;2.

- M. Zhao, and D. E. Waliser, 2012a: Modulation of tropical cyclones over the eastern Pacific by the intraseasonal variability simulated in an AGCM. J. Climate, 25, 6524-6538, https://doi.org/10.1175/JCLI-D-11-00531.1.

, and Coauthors, 2012b: Simulation of the intraseasonal variability over the Eastern Pacific ITCZ in climate models. Climate Dyn., 39, 617-636, https://doi.org/10.1007/s00382-011-1098-x.

Kerns, B. W., and E. J. Zipser, 2009: Four years of tropical ERA-40 vorticity maxima tracks. Part II: Differences between developing and nondeveloping disturbances. Mon. Wea. Rev., 137, 2576-2591, https://doi.org/10.1175/2008MWR2545.1. and S. S. Chen, 2013: Cloud clusters and tropical cyclogenesis: Developing and nondeveloping systems and their large-scale environment. Mon. Wea. Rev., 141, 192-210, https://doi.org/ 10.1175/MWR-D-11-00239.1.

Kim, H.-M., C. D. Hoyos, P. J. Webster, and I.-S. Kang, 2008: Sensitivity of MJO simulation and predictability to sea surface 
temperature variability. J. Climate, 21, 5304-5317, https:// doi.org/10.1175/2008JCLI2078.1.

Klotzbach, P. J., 2010: On the Madden-Julian oscillation-Atlantic hurricane relationship. J. Climate, 23, 282-293, https://doi.org/ 10.1175/2009JCLI2978.1.

— tropical cyclone activity by the Madden-Julian oscillation (MJO) from 1905 to 2011. J. Climate, 28, 204-217, https:// doi.org/10.1175/JCLI-D-14-00509.1.

Knapp, K. R., M. C. Kruk, D. H. Levinson, H. J. Diamond, and C. J. Neumann, 2010: The International Best Track Archive for Climate Stewardship (IBTrACS): Unifying tropical cyclone best track data. Bull. Amer. Meteor. Soc., 91, 363-376, https:// doi.org/10.1175/2009BAMS2755.1.

_- and Coauthors, 2011: Globally gridded satellite observations for climate studies. Bull. Amer. Meteor. Soc., 92, 893-907, https://doi.org/10.1175/2011BAMS3039.1.

Lee, J.-Y., B. Wang, M. C. Wheeler, X. Fu, D. E. Waliser, and I.-S. Kang, 2013: Real-time multivariate indices for the boreal summer intraseasonal oscillation over the Asian summer monsoon region. Climate Dyn., 40, 493-509, https://doi.org/10.1007/ s00382-012-1544-4.

Leroy, A., and M. C. Wheeler, 2008: Statistical prediction of weekly tropical cyclone activity in the Southern Hemisphere. Mon. Wea. Rev., 136, 3637-3654, https://doi.org/10.1175/ 2008MWR2426.1.

Li, R. C. Y., and W. Zhou, 2013a: Modulation of western North Pacific tropical cyclone activity by the ISO. Part I: Genesis and intensity. J. Climate, 26, 2904-2918, https://doi.org/10.1175/ JCLI-D-12-00210.1.

$\longrightarrow$, and - , 2013b: Modulation of western North Pacific tropical cyclone activity by the ISO. Part II: Tracks and landfalls. J. Climate, 26, 2919-2930, https://doi.org/10.1175/ JCLI-D-12-00211.1.

,-- C. M. Shun, and T. C. Lee, 2017: Change in destructiveness of landfalling tropical cyclones over China in recent decades. J. Climate, 30, 3367-3379, https://doi.org/ 10.1175/JCLI-D-16-0258.1.

Li, T., and B. Wang, 2005: A review on the western North Pacific monsoon: Synoptic-to-interannual variabilities. Terr. Atmos. Oceanic Sci., 16, 285-314, https://doi.org/10.3319/ TAO.2005.16.2.285(A).

Liebmann, B., and C. A. Smith, 1996: Description of a complete (interpolated) outgoing longwave radiation dataset. Bull. Amer. Meteor. Soc., 77, 1275-1277.

- , H. H. Hendon, and J. D. Glick, 1994: The relationship between tropical cyclones of the western Pacific and Indian Oceans and the Madden-Julian oscillation. J. Meteor. Soc. Japan, 72, 401-412, https://doi.org/10.2151/jmsj1965.72.3_401.

Lin, J.-L., and Coauthors, 2006: Tropical intraseasonal variability in 14 IPCC AR4 climate models. Part I: Convective signals. J. Climate, 19, 2665-2690, https://doi.org/10.1175/JCLI3735.1.

Lin, Y.-L., and C.-S. Lee, 2011: An analysis of tropical cyclone formations in the South China Sea during the late season. Mon. Wea. Rev., 139, 2748-1760, https://doi.org/10.1175/2011MWR3495.1.

Liu, P., Q. Zhang, C. Zhang, Y. Zhu, M. Khairoutdinov, H.-M. Kim, C. Schumacher, and M. Zhang, 2016: A revised real-time multivariate MJO index. Mon. Wea. Rev., 144, 627-642, https://doi.org/10.1175/MWR-D-15-0237.1.

Madden, R. A., and P. R. Julian, 1971: Detection of a 40-50 day oscillation in the zonal wind in the tropical Pacific. J. Atmos. Sci., 28, 702-708, https://doi.org/10.1175/1520-0469(1971)028<0702: DOADOI $>2.0 . \mathrm{CO} ; 2$.
, and - 1972: Description of global-scale circulation cells in the tropics with a 40-50 day period. J. Atmos. Sci., 29, 1109-1123, https://doi.org/10.1175/1520-0469(1972)029<1109: DOGSCC $>2.0$. CO 2 .

Neena, J. M., D. E. Waliser, and X. Jiang, 2017: Model performance metrics and process diagnostics for boreal summer intraseasonal variability. Climate Dyn., 48, 1661-1683, https:// doi.org/10.1007/s00382-016-3166-8.

North, G. R., T. L. Bell, R. F. Cahalan, and F. J. Moeng, 1982: Sampling errors in the estimation of empirical orthogonal functions. Mon. Wea. Rev., 110, 699-706, https://doi.org/ 10.1175/1520-0493(1982)110<0699:SEITEO > 2.0.CO;2.

Rashid, H. A., H. H. Hendon, M. C. Wheeler, and O. Alves, 2011: Prediction of the Madden-Julian oscillation with the POAMA dynamical prediction system. Climate Dyn., 36, 649-661, https://doi.org/10.1007/s00382-010-0754-x.

Slingo, J. M., and Coauthors, 1996: Intraseasonal oscillations in 15 atmospheric general circulation models: Results from an AMIP diagnostic subproject. Climate Dyn., 12, 325-357, https://doi.org/10.1007/BF00231106.

Teng, H.-F., C.-S. Lee, and H.-H. Hsu, 2014: Influence of ENSO on formation of tropical cloud clusters and their development into tropical cyclones in the western North Pacific. Geophys. Res. Lett., 41, 9120-9126, https://doi.org/10.1002/2014GL061823.

Waliser, D. E., K. M. Lau, W. Stern, and C. Jones, 2003: Potential predictability of the Madden-Julian oscillation. Bull. Amer. Meteor. Soc., 84, 33-50, https://doi.org/10.1175/BAMS-84-1-33.

— project. Bull. Amer. Meteor. Soc., 87, 425-431.

Wang, B., and H. Rui, 1990: Synoptic climatology of transient tropical intraseasonal convection anomalies: 1975-1985. Meteor. Atmos. Phys., 44, 43-61, https://doi.org/10.1007/BF01026810.

Weare, B. C., and J. S. Nasstrom, 1982: Examples of extended empirical orthogonal function analyses. Mon. Wea. Rev., 110, 481-485, https://doi.org/10.1175/1520-0493(1982)110<0481: EOEEOF $>2.0 . \mathrm{CO} ; 2$.

Wheeler, M. C., and H. H. Hendon, 2004: An all-season real-time multivariate MJO index: Development of an index for monitoring and prediction. Mon. Wea. Rev., 132, 1917-1932, https://doi.org/ 10.1175/1520-0493(2004)132<1917:AARMMI>2.0.CO;2.

,,-- S. Cleland, H. Meinke, and A. Donald, 2009: Impacts of the Madden-Julian oscillation on Australian rainfall and circulation. J. Climate, 22, 1482-1498, https://doi.org/10.1175/ 2008JCLI2595.1.

Wilks, D. S., 2006: On "field significance" and the false discovery rate. J. Appl. Meteor. Climatol., 45, 1181-1189, https://doi.org/ 10.1175/JAM2404.1.

Yasunari, T., 1979: Cloudiness fluctuations associated with the Northern Hemisphere summer monsoon. J. Meteor. Soc. Japan, 57, 227-242, https://doi.org/10.2151/jmsj1965.57.3_227.

Zehr, R. M., 1992: Tropical cyclogenesis in the western North Pacific. Ph.D. thesis, Colorado State University, 91 pp.

Zhang, Q., L. Wu, and Q. Liu, 2009: Tropical cyclone damages in China 1983-2006. Bull. Amer. Meteor. Soc., 90, 489-495, https://doi.org/10.1175/2008BAMS2631.1.

Zhao, H., and G. B. Raga, 2014: The influence of large-scale circulations on the extremely inactive tropical cyclone activity in 2010 over the western North Pacific. Atmósfera, 27, 353-365, https://doi.org/10.1016/S0187-6236(14)70034-7.

— equatorial Rossby wave on the western North Pacific tropical cyclones activity. Int. J. Climatol., 38, 932-948, https://doi.org/ $10.1002 /$ joc.5220. 
_, X. Jiang, and L. Wu, 2015a: Modulation of northwest Pacific tropical cyclone genesis by the intraseasonal variability. J. Meteor. Soc. Japan, 93, 81-97, https://doi.org/10.2151/ jmsj.2015-006.

_, R. Yoshida, and G. B. Raga, 2015b: Impact of the MaddenJulian oscillation on western North Pacific tropical cyclogenesis associated with large-scale patterns. J. Appl. Meteor. Climatol., 54, 1413-1429, https://doi.org/10.1175/JAMC-D-14-0254.1.

__ X. Jiang, and L. Wu, 2016: Boreal summer synoptic-scale waves over the western North Pacific in multimodel simulations. J. Climate, 29, 4487-4508, https://doi.org/10.1175/ JCLI-D-15-0696.1.
— G. B. Raga, and P. J. Klotzbach, 2018a: Impact of the boreal summer quasi-biweekly oscillation on eastern North Pacific tropical cyclone activity. Int. J. Climatol., 38, 1353-1365, https://doi.org/10.1002/joc.5250.

, X. Duan, G. B. Raga, and F. Sun, 2018b: Potential large-scale forcing mechanisms driving enhanced North Atlantic tropical cyclone activity since the mid-1990s. J. Climate, 31, 1377-1397, https://doi.org/10.1175/JCLI-D-17-0016.1.

—, X. Jiang, L. Wu, and P. J. Klotzbach, 2018c: Multi-scale interactions of equatorial waves associated with tropical cyclogenesis over the western North Pacific. Climate Dyn., https:// doi.org/10.1007/s00382-018-4307-z, in press. 